\title{
Diversity of Leptospira spp. in Rats and Environment from Urban Areas of Sarawak, Malaysia
}

\author{
Chai Fung Pui, ${ }^{1}$ Lesley Maurice Bilung, ${ }^{1}$ Kasing Apun, ${ }^{1}$ and Lela Su' ${ }^{2}{ }^{2}$ \\ ${ }^{1}$ Department of Molecular Biology, Faculty of Resource Science and Technology, Universiti Malaysia Sarawak, \\ 94300 Kota Samarahan, Sarawak, Malaysia \\ ${ }^{2}$ Faculty of Medicine and Health Sciences, Universiti Malaysia Sarawak, 94300 Kota Samarahan, Sarawak, Malaysia \\ Correspondence should be addressed to Lesley Maurice Bilung; mblesley@unimas.my
}

Received 11 November 2016; Revised 9 January 2017; Accepted 6 February 2017; Published 28 February 2017

Academic Editor: Jean-Paul J. Gonzalez

Copyright (C) 2017 Chai Fung Pui et al. This is an open access article distributed under the Creative Commons Attribution License, which permits unrestricted use, distribution, and reproduction in any medium, provided the original work is properly cited.

\begin{abstract}
Various prevalence studies on Leptospira in animals and humans, as well as environmental samples, had been conducted worldwide, including Malaysia. However, limited studies have been documented on the presence of pathogenic, intermediate, and saprophytic Leptospira in selected animals and environments. This study was therefore conducted to detect Leptospira spp. in rats, soil, and water from urban areas of Sarawak using the polymerase chain reaction (PCR) method. A total of 107 rats, 292 soil samples, and 324 water samples were collected from April 2014 to February 2015. Pathogenic Leptospira was present in 5.6\% (6/107) of rats, 11.6\% $(34 / 292)$ of soil samples, and $1.9 \%$ (6/324) of water samples. Intermediate Leptospira was present in $2.7 \%(8 / 292)$ of soil samples and $1.9 \%(6 / 324)$ of water samples. Saprophytic Leptospira was present in $10.3 \%(11 / 107)$ of rats, $1.4 \%(4 / 292)$ of soil samples, and $0.3 \%$ (1/324) of water samples. From this study, 76 Leptospira spp. were isolated. Based on DNA sequencing, the dominant Leptospira spp. circulating in urban areas of Sarawak are pathogenic Leptospira noguchii, intermediate Leptospira wolffii serovar Khorat, and saprophytic Leptospira meyeri, respectively. Overall, this study provided important surveillance data on the prevalence of Leptospira spp. from rats and the environment, with dominant local serovars in urban areas of Sarawak.
\end{abstract}

\section{Introduction}

Leptospirosis is a zoonotic disease with worldwide distribution and caused by pathogenic Leptospira, which results in significant public health problem worldwide $[1,2]$. The genus Leptospira consists of 20 species, with more than 300 serovars, grouped into 20 serogroups [3]. Based on the pathogenicity, they can be divided into three major clades, namely, pathogenic, saprophytic (nonpathogenic), and intermediate (unclear pathogenicity) [2]. The pathogenicity status of intermediate Leptospira remains a debate matter. For instance, hamsters inoculated with intermediate L. inadai and L. licerasiae do not cause any clinical manifestation of leptospirosis although both recovered from patients [4].

Humans usually get infected through direct contact with the infected animal urine via mucous membrane and exposed skin or indirect contact by exposure to the contaminated soil, water, and food [5-7]. Normally, maintenance hosts are asymptomatic while accidental hosts like humans may suffer a wide range of clinical manifestation such as renal failure, hepatic failure, severe pulmonary haemorrhage, and even death [8]. The overall case mortality rate in humans ranges from 1 to $5 \%$ and the elderly are claimed to have higher infection risk of leptospirosis [9]. Incidence rates are often underestimated because of the relative inaccessibility, lack of rapid diagnostics, and insufficient awareness of leptospirosis [10].

Similar prevalence studies on Leptospira spp. had been conducted in Malaysia in recent years. Leptospira had been isolated from urban rats of Kuala Lumpur [11] as well as soil and water from urban sites in Peninsular Malaysia [12]. The presence of Leptospira spp. was also reported in National Service Training Centres of Peninsular Malaysia [13]. Moreover, Thayaparan et al. [14] reported the presence of Leptospira spp. in wildlife around tourism areas in Sarawak. Our previous study highlighted the presence of Leptospira spp. in national parks [15]. The presence of Leptospira spp. in this area posed the risk of transmission and infection to humans. Since this study on the detection of Leptospira spp. in rats, soil and 
water from urban areas is first reported in Sarawak, the data obtained is definitely important to provide an insight on the status of Leptospira spp. in Sarawak.

Current diagnostic methods for Leptospira spp. usually rely on the demonstration of serum antibodies by microscopic agglutination test (MAT). However, this method is time-consuming, requires live strain of Leptospira in exponential culture phase, and gives subjective interpretation of result [16]. The use of PCR is therefore gaining more popularity over MAT now. PCR, as direct genome detection method, offers various key advantages such as reduced contamination, increased detection accuracy, faster detection, and elimination of the need to use many antigens [6]. Besides, the use of PCR is critical particularly at early stage of infection and acute stage of illness before antibodies are detectable. The early diagnosis of leptospirosis can reduce the complications due to leptospirosis and prevent fatality [17].

Many different primer sets had been applied in the detection of Leptospira. In this study, LipL32, rRNA, and rrs genes were targeted as reported in our previous study [15]. LipL32 gene is a major outer membrane lipoprotein of Leptospira. The lipoprotein is highly conserved among pathogenic Leptospira and considered as virulence factor where higher levels of LipL32 are expressed in Leptospira during acute lethal infections than Leptospira cultured in vitro $[8,18]$. rRNA gene is very conserved throughout the bacterial kingdom. The primer set targeting $16 S r R N A$ genes is genus-specific and useful in epidemiological study [19]. The primer set designed within the rrs gene encoding 16S rRNA is specific to saprophytic Leptospira [20].

The objective of this study was to determine the diversity of Leptospira spp. in rats, soil, and water samples from urban areas of Sarawak using PCR. This study also aimed to disseminate information on the dominant Leptospira serovars circulating in Sarawak so that control and preventive measures for this disease can be taken effectively.

\section{Materials and Methods}

2.1. Study Sites. This study focused on urban areas in Sarawak which are usually characterized by high density of humans population. According to Population and Housing Census 2010 by Department of Statistics Malaysia (2015), urban area is defined as gazetted areas with their adjoining built-up areas, which had a combined population of 10,000 or more at the time of the Census 2010 or the special development area that can be identified, which at least had a population of 10,000 with at least $60 \%$ of population (aged 15 years and above) being involved in nonagricultural activities.

The study sites (Figure 1) included public university, villages, residential areas, commercial centres, hawker centres, and markets. The selection of study sites was based on the recent reports of leptospirosis outbreak, environmental exposure due to humans activities, the suitability of the habitat for the rats breeding, and its likelihood of transmitting the disease. A total of 107 rats, 292 soil samples and 324 water samples were collected from April 2014 to February 2015.

In brief, the cage traps were set randomly near the garbage disposal areas, landfills, surrounding of housing areas, and

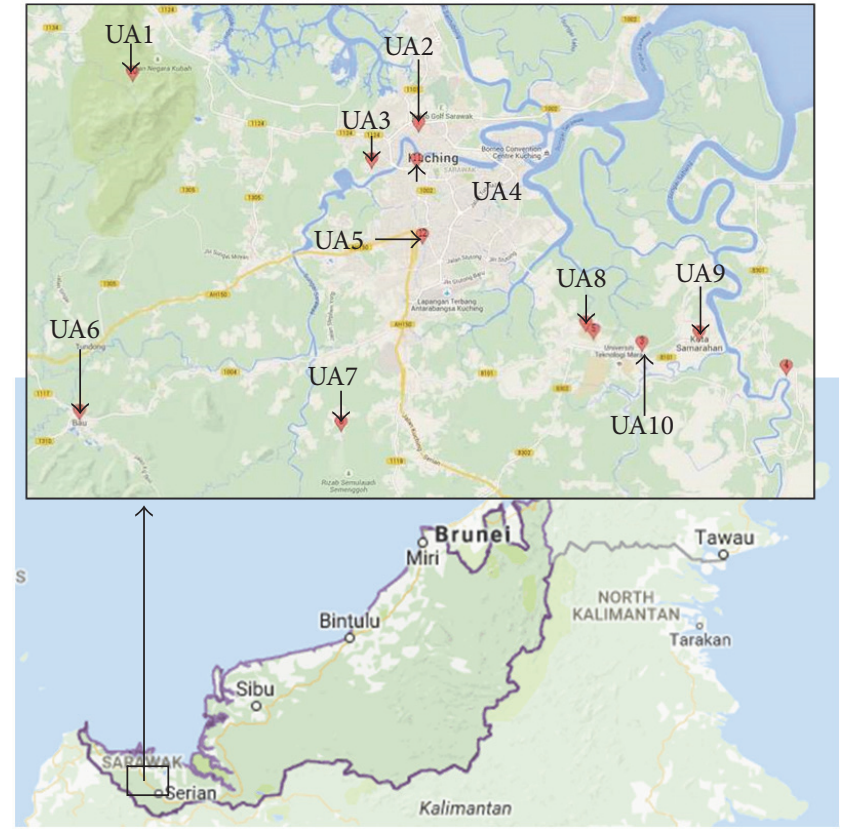

FIGURE 1: Location of all the urban areas (UA) examined in this study (MapCustomizer, 2016). UA1, UA2, UA3, and UA7 are densely populated villages; UA4 is a famous market near villages; UA5 is a densely populated residential area with prominent hawker centres; UA6 and UA9 are small villages; UA8 is a public university; and $\mathrm{UA} 10$ is a residential area.

store room. Soil samples were collected from the surrounding of housing areas, landfills, open field, and surrounding of lake. Water samples were collected from drain effluent, river, lake, and puddle.

2.2. Rat Trapping and Species Identification. The rats were caught alive using rectangular wire cage traps measuring $15 \times$ $12.5 \times 29 \mathrm{~cm}$. Each trapping session took at least three consecutive days where the cage traps with baits were set up on the first day before checking for the capturing yield on the consecutive days. All the trapped rats under the family Muridae were euthanized humanely by placing them into a cloth bag containing cotton wool soaked with chloroform. They were further identified based on phenotypic characteristics such as fur colour (ventral and dorsal) and morphological measurements such as ear length, hind foot, tail length, and head body length [21].

2.3. Rat Samples Collection. Selected organs such as kidney and liver were removed from euthanized rats using sterile blade. A small piece of tissue was inoculated into modified semisolid Ellinghausen-McCullough-Johnson-Harris (EMJH) media with $100 \mu \mathrm{g} / \mathrm{mL}$ 5-fluorouracil. All the enriched cultures were incubated aerobically at room temperature for 3 months. They were examined for the presence of Leptospira using polymerase chain reaction (PCR) every month $[7,11]$.

2.4. Soil and Water Samples Collection. Approximately $20 \mathrm{~g}$ soil and $50 \mathrm{~mL}$ water samples were collected. Soil samples 
were mixed vigorously using sterile distilled water and allowed to settle for 15 minutes prior to filtration using sterile $0.2 \mu \mathrm{m}$ pore size membrane filter (Sartorius AG, Germany). Water samples were filtered directly using the same type of membrane filter. About $1 \mathrm{~mL}$ of the samples was inoculated into modified semisolid EMJH media with $100 \mu \mathrm{g} / \mathrm{mL} 5$ fluorouracil. They were incubated aerobically at room temperature for 1 month $[12,13]$.

2.5. Molecular Detection of Leptospira spp. DNA extraction was carried out using Wizard ${ }^{\mathrm{TM}}$ Genomic DNA Purification Kit (Promega Corporation, USA) following the manufacturer's instructions prior to specific PCR amplification. Three sets of primers were used to target LipL32, 16S rRNA, and rrs genes in pathogenic, intermediate, and saprophytic Leptospira, respectively [15]. Pathogenic Leptospira noguchii strain LT796, intermediate Leptospira wolffii serovar Khorat strain Khorat-H2, and saprophytic Leptospira meyeri strain Sant-1 were used as positive controls.

The $25 \mu \mathrm{L}$ reaction mixtures included $5 \mu \mathrm{L}$ of $5 \mathrm{x}$ PCR buffer, $2.0 \mathrm{mM} \mathrm{MgCl}, 0.4 \mu \mathrm{M}$ of each primer pair, $0.2 \mathrm{mM}$ of dNTP mix, $1.25 \mathrm{U}$ of Taq DNA polymerase (Promega Corporation, USA), and $5 \mu \mathrm{L}$ of DNA template. The cycling conditions included initial denaturation at $95^{\circ} \mathrm{C}$ for $2 \mathrm{~min}$, 35 cycles of each of denaturation at $95^{\circ} \mathrm{C}$ for $1 \mathrm{~min}$, primer annealing at $55^{\circ} \mathrm{C}$ for $30 \mathrm{sec}$, and extension at $72^{\circ} \mathrm{C}$ for $1 \mathrm{~min}$, further extension at $72^{\circ} \mathrm{C}$ for $5 \mathrm{~min}$, and indefinite holding period at $4^{\circ} \mathrm{C}$. Electrophoresis was then carried out using $2 \%$ agarose gel in 1x TBE buffer.

2.6. Identification of Leptospira spp. At least one positive sample from each study site was chosen for DNA sequencing, depending on the availability of the sample sources. The amplicons from representative positive samples were subjected to commercial facility for sequencing (First BASE Laboratories Sdn Bhd, Malaysia). The sequencing data were compared with the GenBank database using nucleotide BLAST from National Center for Biotechnology Information (NCBI).

\section{Results}

The agarose gel image for representative PCR amplicons in this study is shown in Figure 2. The prevalence of Leptospira spp. in rats, soil, and water samples is tabulated in Table 1. One hundred and seven rats comprising seven species were successfully collected. These rats consisted of $54.2 \%$ males and $75.7 \%$ adults. It was noticed that $87.9 \%$ of the total rats were Rattus rattus.

In this study, eleven female and twelve adult rats were Leptospira positive. Pathogenic Leptospira was present in six Rattus rattus, thirty-four soil samples, and six water samples. Eight soil samples and six water samples were detected with intermediate Leptospira. Saprophytic Leptospira was present in eleven rats, four soil samples, and one water sample.

Using PCR amplification, a total of $6.4 \%(46 / 723)$ pathogenic, $1.9 \%$ (14/723) intermediate, and 2.2\% (16/723) saprophytic Leptospira were detected in rats, soil, and water samples from urban areas of Sarawak. The representative
TABLE 1: Prevalence of Leptospira spp. by PCR in rats, soil, and water samples collected in this study.

\begin{tabular}{lcccccc}
\hline \multirow{2}{*}{ Sample } & \multicolumn{2}{c}{ Pathogenic } & \multicolumn{2}{c}{ Intermediate } & \multicolumn{2}{c}{ Saprophytic } \\
& Number. $^{\mathrm{a}}$ & $\%^{\mathrm{b}}$ & Number. $^{\mathrm{a}}$ & $\%^{\mathrm{b}}$ & Number. $^{\mathrm{a}}$ & $\%^{\mathrm{b}}$ \\
\hline Rat & $6 / 107$ & 5.6 & $0 / 107$ & 0.0 & $11 / 107$ & 10.3 \\
Soil & $34 / 292$ & 11.6 & $8 / 292$ & 2.7 & $4 / 292$ & 1.4 \\
Water & $6 / 324$ & 1.9 & $6 / 324$ & 1.9 & $1 / 324$ & 0.3 \\
\hline
\end{tabular}

Note: ${ }^{\mathrm{a}}$ number of positive samples/number of samples collected; ${ }^{\mathrm{b}}$ prevalence (in \%) of positive samples among the samples collected.

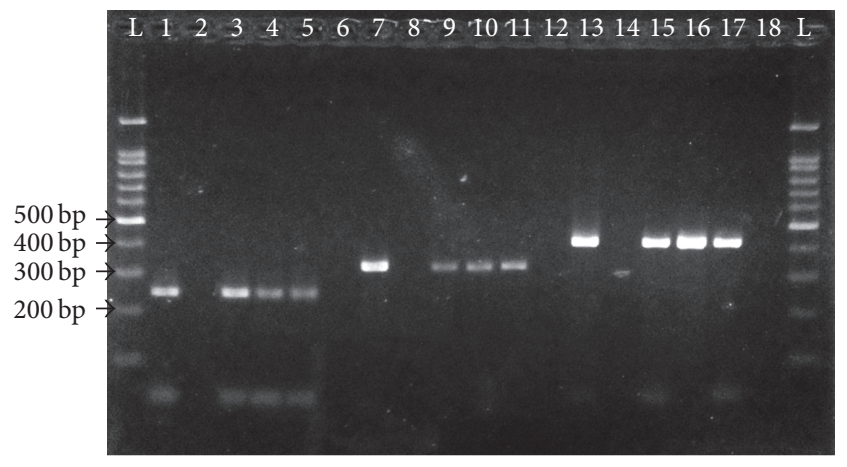

FIGURE 2: Representative gel image of PCR amplification. Lanes L, 100 bp DNA ladder; lanes 1, 7, and 13, positive controls; lanes 2, 8 , and 14, negative controls; lanes 3 to 5, positive PCR amplicons specific to saprophytic Leptospira at $240 \mathrm{bp}$; lanes 9 to 11, positive PCR amplicons specific to intermediate Leptospira at $331 \mathrm{bp}$; lanes 15 to 17, positive PCR amplicons specific to pathogenic Leptospira at 423 bp; lanes 6, 12, and 18, negative PCR amplicons.

positive samples were made up of sixteen pathogenic Leptospira (four rats, eight soil samples, and four water samples), four intermediate Leptospira (one soil sample and three water samples), and ninesaprophytic Leptospira (six rats, two soil samples, and one water sample).

The nucleotide BLAST results for the representative positive samples were tabulated in Table 2 . The degree of homology for pathogenic Leptospira varied from $75 \%$ to $91 \%$. Based on phylogeny, Leptospira interrogans serovar Icterohaemorrhagiae and Leptospira noguchii are present dominantly in the rats. The dominant pathogenic Leptospira found in soil and water samples are Leptospira noguchii and Leptospira interrogans serovar Hardjo, respectively.

Positive samples showed $96 \%$ to $99 \%$ identity with reported sequences in intermediate Leptospira. Leptospira wolffi serovar Khorat is the dominant intermediate Leptospira in soil and water samples from urban areas. Apart from that, a high homology ranging from $95 \%$ to $99 \%$ was obtained for positive samples of saprophytic Leptospira. Leptospira meyeri is present in all the rats, soil, and water samples.

\section{Discussion}

In this study, Rattus rattus is the dominant rat species found in urban areas of Sarawak. This rat species is commonly known as black rat which adapts very well to the climatic and environmental conditions. In a study where 90 rodents 


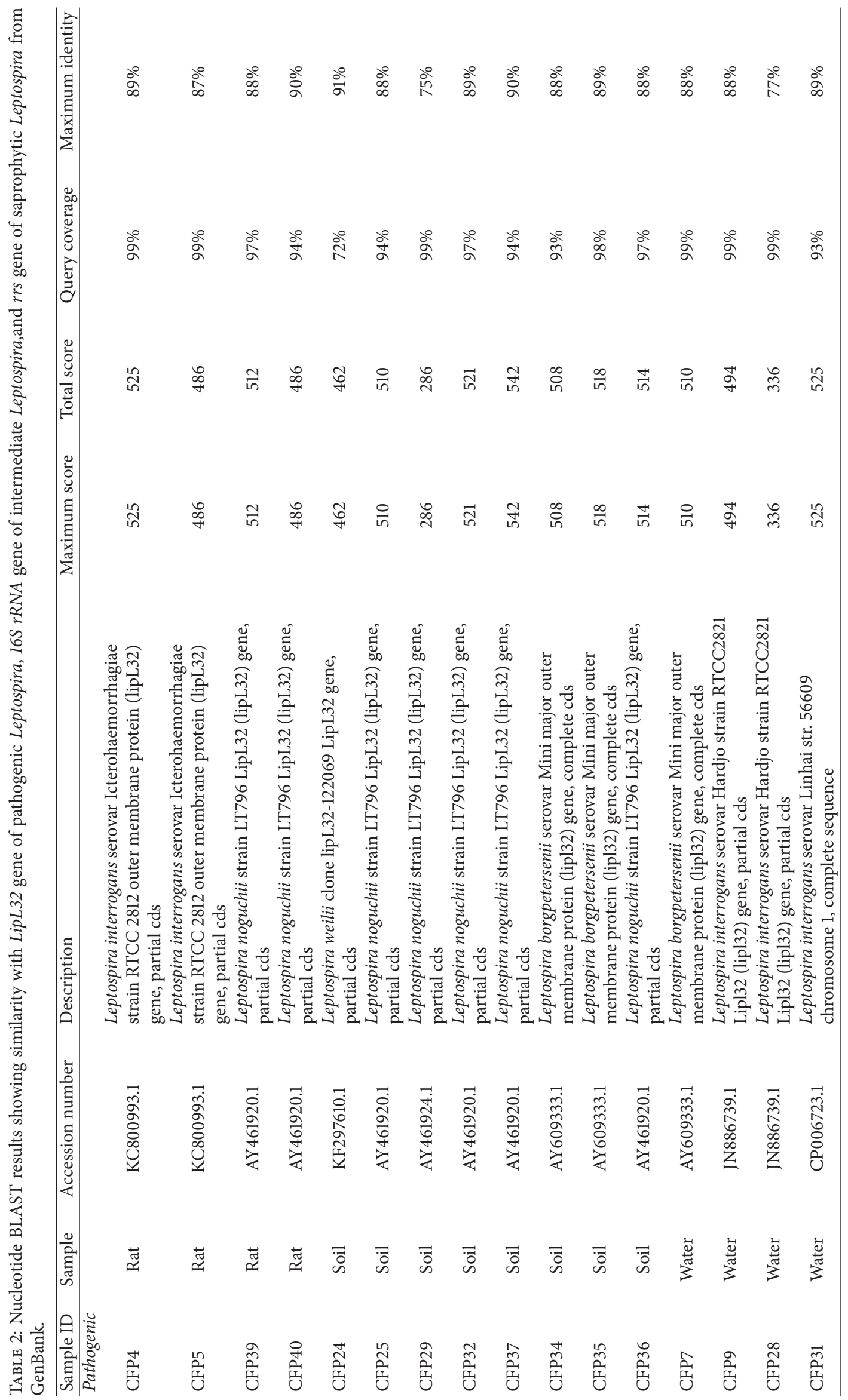




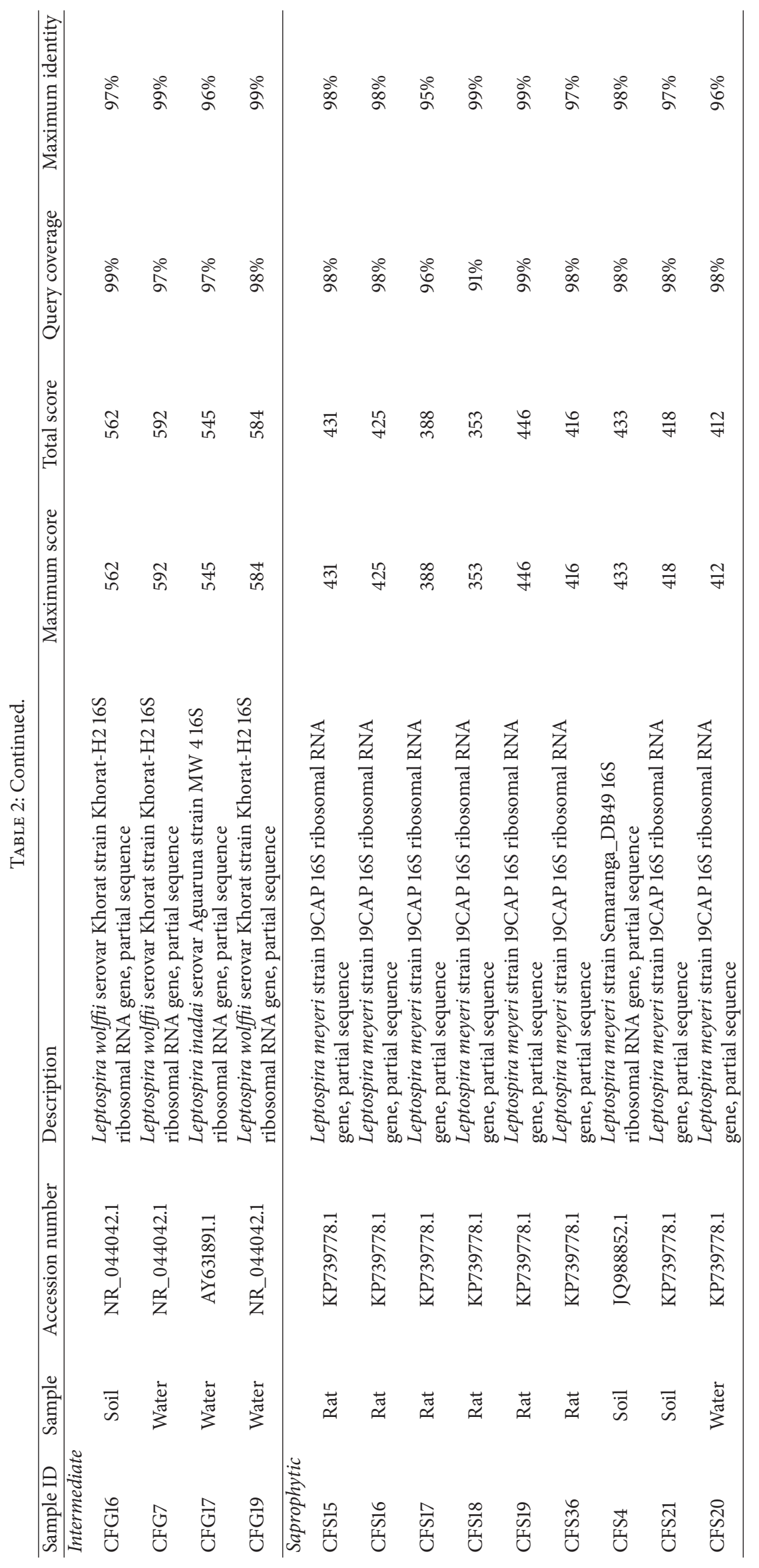


were trapped in Cotonou, West Africa, Rattus rattus is the rat species with the greatest distribution as it spreads inland and is present in small towns and villages [7]. Rattus rattus was also reported to be one of the principal domestic rats found in urban areas, open fields, and residential areas of Malaysia. Previous study on the distribution of urban rodents in Kuala Lumpur indicated that $91.8 \%$ (89/97) rodents trapped were Rattus rattus [22].

From the total 17 Leptospira positive rats, a greater number of female $(64.7 \%)$ and adult $(70.6 \%)$ rats were detected. This is contrary with the finding by Mosallanejad et al. [23] who studied the seroprevalence of Leptospira in 120 wild rats in Iran. They reported that positive Leptospira was found in $2.5 \%$ male and $0.83 \%$ female rats. Nonetheless, our finding is in agreement with previous study by Benacer et al. [11] who stated that adult rats $(7.2 \%)$ were infected more frequently than juvenile rats (5.4\%). This is because adult rats are more aggressive during fighting which facilitates the transmission of Leptospira among them.

Pathogenic Leptospira was found in three rats captured and four water samples from UA8, a public university. Two water samples and one soil sample were contaminated by intermediate and saprophytic Leptospira, respectively. The presence of Leptospira in public university suggested that the occurrence of Leptospira may be related to humans settlement due to generation of significant amount of waste [24]. Indiscriminate disposal of food waste can lead to breeding of rats and other domestic animals.

In UA9, one of the small villages, saprophytic Leptospira was present in four rats captured whereas two soil samples and one water sample were contaminated by pathogenic Leptospira. These two contaminated soil samples were collected from surrounding of houses whereas contaminated water sample was collected from the river in this village. Many domesticated animals such as dogs, cats, and chickens can be found here. Since only environmental samples but no rats were detected with pathogenic Leptospira, it implied the possibility of domestic animals as the reservoir for Leptospira. This can result in the transmission of Leptospira through indirect contact with urine-contaminated environment [16]. Our finding is supported by Issazadeh et al. [25] who studied the distribution of Leptospira in surface waters among different region in Guilan Province, China. They reported a higher frequency of Leptospira in a region with more domestic animals such as cow, sheep, and horse. These animals are excellent reservoirs for Leptospira.

Sampling at a few densely populated villages (UA1, UA2, UA3, and UA7) and residential area (UA10) showed that three rats were positive towards pathogenic Leptospira and five rats were positive towards saprophytic Leptospira. Low prevalence of Leptospira spp. in residential area is consistent with the finding by Khairani-Bejo et al. [17] who reported that only $3.1 \%(1 / 32)$ rat captured in residential area of Serdang, Selangor was infected with Leptospira. Six soil samples collected from the surrounding of houses were contaminated by pathogenic Leptospira. One water sample contaminated with pathogenic Leptospira was collected from an artificial pond in residential area. From the observation during sampling, this artificial pond contains stagnant water which favours the survival of Leptospira. Higher concentration of Leptospira was found in stagnant river water than in rainwater or underground water [26].

Only eight soil samples and four water samples from a small village, UA6, were positive for intermediate Leptospira. These soil samples were collected from forest area whereas the water samples were collected from a small river in the village. There were nine soil samples with positive pathogenic Leptospira collected from landfills and surrounding of lake in commercial centres. Landfills with garbage containers have abundance of food resources which attract a lot of rats to forage. Rubbish can be found at the surrounding of lake. It was stipulated that the hygiene at this area is very poor. Improper waste management strongly encouraged the proliferation of Leptospira [12].

Five soil samples collected from UA5, a densely populated residential area with prominent hawker centres, were contaminated by pathogenic Leptospira. In another famous market, UA4, which comprised wet and dry markets, cafeteria, and food court, two rats captured carried saprophytic Leptospira. A total of $40.0 \%$ (12/30) soil samples were contaminated by pathogenic Leptospira. Besides, saprophytic Leptospira was present in three soil samples and one water sample in this market. Soil samples were mainly collected from open field in this large market whereas the water sample was collected from the river. The accumulation of garbage and food waste is a common scenario in market. This attracts rodents and domestic animals to populate and become potential reservoirs for Leptospira. From the observation during sampling, it was proven that the garbage and rubbish were disposed everywhere by public. Although the rats captured here did not carry pathogenic Leptospira, there is still a risk of infection to humans as the environment is highly contaminated with pathogenic Leptospira.

The presence of pathogenic Leptospira in rats was not surprised as the isolation of this spirochete from rats was first reported in 1917 [27]. The presence of Leptospira especially pathogenic strains in environmental soil and water is an index of leptospirosis in rats or domestic animals which have access to these sources [28]. Besides rats, other domestic animals may serve as reservoirs for Leptospira spp. and contaminate the environment in these study sites. The finding from previous researcher indicated that higher prevalence of Leptospira was detected in other animals such as cattle (53.8\%), horse (27.9\%), buffalo $(58.7 \%)$, and donkey $(40.0 \%)$ than in rats (3.3\%) in Ahvaz, Iran. This is because those animals which live in groups near water may have additional access to the contaminated environment and stagnant water than rats [23].

The dominant pathogenic Leptospira serovar circulating in the urban areas is Leptospira noguchii. L. noguchii has been isolated from multiple animal species in Argentina, Barbados, and Nicaragua as well as from humans in the United States of America and neighbouring Panama and Peru [29]. Previous study by Silva et al. [30] also reported the isolation of three Leptospira noguchii strains from Brazil, of which two humans were infected by leptospirosis after contact with dogs and rats and one fatal leptospirosis case involving a dog. Nonetheless, Leptospira Icterohaemorrhagiae was the main serovar detected in the serum samples of rats captured in 
national service training centres in Kelantan and Terengganu [31]. This serovar is often associated with rodents especially rats worldwide [17]. Alexander et al. [32] also stated that serovar Icterohaemorrhagiae is the most common pathogenic strain found in Malaysian water.

Our result indicated that Leptospira wolffi serovar Khorat is the dominant intermediate Leptospira circulating in urban areas. It was previously isolated from wildlife and humans from Iran, India, Thailand, and Sabah [33]. Benacer et al. [12] isolated Leptospira wolffii from University Malaya Lake in Peninsular Malaysia. The presence of intermediate species such as Leptospira wolffii in clinical humans samples and animals indicated the circulation of this strain which may play a role in the transmission cycle within animal reservoir and humans [2]. On the other hand, Leptospira meyeri is found to be dominant among saprophytic Leptospira in urban areas. The same strain had been isolated from the soil at Pantai Dalam, Kuala Lumpur [12].

Different Leptospira serovars may circulate in different reservoirs or environment in a particular geographical region [2]. The knowledge of locally circulating serovars and their reservoirs is important to the epidemiological understanding of this disease in a region [34]. Dominant serovars can be changed in a region from time to time. This is because old and well-established serovars may adapt themselves into new hosts, which subsequently create risk of infection $[35,36]$.

As a whole, this study provided an insight on the diversity of Leptospira spp. in urban areas of Sarawak, Malaysia. Various precaution measures such as rodent control campaign should be taken to reduce the risk of leptospirosis to humans.

\section{Competing Interests}

The authors declare that they have no competing interests.

\section{Acknowledgments}

This study was funded by the Ministry of Higher Education Malaysia under Fundamental Research Grant Scheme FRGS/SG03(01)/970/2013(11) and UNIMAS internal grant under Ph.D. Student Fund F07(DPP21)/1191/2014(21). Special acknowledgement goes to the Commission of the City of Kuching North and other relevant authorities for the approval to collect samples in urban sites of Sarawak. The authors also appreciate the assistance given by lab assistants, postgraduates, and undergraduates from the Department of Molecular Biology and Department of Zoology in the Faculty of Resource Science and Technology, Universiti Malaysia Sarawak.

\section{References}

[1] A. J. A. McBride, D. A. Athanazio, M. G. Reis, and A. I. Ko, "Leptospirosis," Current Opinion in Infectious Diseases, vol. 18, no. 5, pp. 376-386, 2005.

[2] V. Balamurugan, N. L. Gangadhar, N. Mohandoss et al., "Characterization of leptospira isolates from animals and humans: phylogenetic analysis identifies the prevalence of intermediate species in India," SpringerPlus, vol. 2, no. 1, pp. 1-9, 2013.
[3] A. Mayer-Scholl, J. A. Hammerl, S. Schmidt et al., "Leptospira spp. in rodents and shrews in Germany," International Journal of Environmental Research and Public Health, vol. 11, no. 8, pp. 7562-7574, 2014.

[4] G. M. Cerqueira and M. Picardeau, "A century of Leptospira strain typing," Infection, Genetics and Evolution, vol. 9, no. 5, pp. 760-768, 2009.

[5] P. N. Levett, "Leptospirosis," Clinical Microbiology Reviews, vol. 14, no. 2, pp. 296-326, 2001.

[6] A. Ahmed, H. L. B. M. Klaasen, M. van der Veen, H. van der Linden, M. G. A. Goris, and R. A. Hartskeerl, "Evaluation of real-time PCR and culturing for the detection of leptospires in canine samples," Advances in Microbiology, vol. 2, no. 2, pp. 162$170,2012$.

[7] G. Houemenou, A. Ahmed, R. Libois, and R. A. Hartskeerl, "Leptospira spp. prevalence in small mammal populations in Cotonou, Benin,” ISRN Epidemiology, vol. 2013, Article ID 502638, 8 pages, 2013.

[8] K. V. Evangelista and J. Coburn, "Leptospira as an emerging pathogen: a review of its biology, pathogenesis and host immune responses," Future Microbiology, vol. 5, no. 9, pp. 1413$1425,2010$.

[9] N. S. Samsi, A. Zainol, D. Darus et al., "Serodiagnosis of leptospirosis in domestic animals and humans," Malaysian Journal of Veterinary Research, vol. 4, no. 2, pp. 21-26, 2013.

[10] A. R. Bharti, J. E. Nally, J. N. Ricaldi et al., "Leptospirosis: a zoonotic disease of global importance," Th eLancet Infectious Diseases, vol. 3, no. 12, pp. 757-771, 2003.

[11] D. Benacer, S. N. M. Zain, F. Amran, R. L. Galloway, and K. L. Thong, "Isolation and molecular characterization of Leptospira interrogans and Leptospira borgpetersenii Isolates from the urban rat populations of Kuala Lumpur, Malaysia," American Journal of Tropical Medicine and Hygiene, vol. 88, no. 4, pp. 704709, 2013.

[12] D. Benacer, P. Y. Who, S. N. M. Zain, F. Amran, and K. L. Thong, "Pathogenic and saprophytic Leptospira species in water and soils from selected urban sites in peninsular Malaysia," Microbes and Environments, vol. 28, no. 1, pp. 135-140, 2013.

[13] F. R. Ridzlan, A. R. Bahaman, S. Khairani-Bejo, and A. R. Mutalib, "Detection of pathogenic Leptospira from selected environment in Kelantan and Terengganu, Malaysia," Tropical Biomedicine, vol. 27, no. 3, pp. 632-638, 2010.

[14] S. Thayaparan, I. D. Robertson, A. Fairuz, L. Suut, and M. T. Abdullah, "Leptospirosis, an emerging zoonotic disease in Malaysia," Malaysian Journal of Pathology, vol. 35, no. 2, pp. 123 132, 2013

[15] C. F. Pui, L. M. Bilung, L. Su'ut, and K. Apun, "Prevalence of Leptospira species in environmental soil and water from national parks in Sarawak, Malaysia," Borneo Journal of Resource Science and Technology, vol. 5, no. 1, pp. 49-57, 2015.

[16] P. Wangroongsarb, W. Petkanchanapong, S. Yasaeng, A. Imvithaya, and P. Naigovit, "Survey of leptospirosis among rodents in epidemic areas of Thailand," The Journal of Tropical Medicine and Parasitology, vol. 25, no. 2, pp. 55-58, 2005.

[17] S. Khairani-Bejo, S. S. Oii, and A. R. Bahaman, "Rats: leptospirosis reservoir in Serdang Selangor residential area," Journal of Animal and Veterinary Advances, vol. 3, no. 2, pp. 66-69, 2004.

[18] A. I. Ko, C. Goarant, and M. Picardeau, "Leptospira: the dawn of the molecular genetics era for an emerging zoonotic pathogen," Nature Reviews Microbiology, vol. 7, no. 10, pp. 736-747, 2009. 
[19] B. Çetinkaya, H. B. Ertaş, H. Öngör, and A. Muz, "Detection of Leptospira species by polymerase chain reaction (PCR) in urine of cattle," Turkish Journal of Veterinary and Animal Sciences, vol. 24, no. 2, pp. 123-130, 2000.

[20] A. Léon, S. Pronost, J. Tapprest et al., "Identification of pathogenic Leptospira strains in tissues of a premature foal by use of polymerase chain reaction analysis," Journal of Veterinary Diagnostic Investigation, vol. 18, no. 2, pp. 218-221, 2006.

[21] J. Payne and C. M. Francis, A Field Guide to the Mammals of Borneo, The Sabah Society, Kota Kinabalu, Malaysia, 2007.

[22] S. Paramasvaran, R. A. Sani, N. M. Amal et al., "Distribution and morphological measurements of wild and urban rodents from four habitats in the states of Selangor and Negeri Sembilan, Malaysia," Malaysian Journal of Veterinary Research, vol. 4, no. 2, pp. 1-12, 2013.

[23] B. Mosallanejad, M. Ghorbanpour Najafabadi, R. Avizeh, and G. Abdollahpour, "A serological survey on leptospiral infection among wild rats (Rattus rattus) of Ahvaz district, southwest of Iran: a preliminary study," Jundishapur Journal of Microbiology, vol. 6, no. 10, Article ID e8333, 2013.

[24] H. Sumanta, T. Wibawa, S. Hadisusanto, A. Nuryati, and H. Kusnanto, "Spatial analysis of Leptospira in rats, water and soil in Bantul District Yogyakarta," Open Journal of Epidemiology, vol. 5, pp. 22-31, 2015.

[25] K. Issazadeh, N. Amirmozaffari, S. Mehrabian, and S. Oryan, "Assessment of the distribution Leptospira spp. in surface waters of Guilan province," American-Eurasian Journal of Scientific Research, vol. 3, no. 2, pp. 147-152, 2008.

[26] C. A. Ganoza, M. A. Matthias, D. Collins-Richards et al., "Determining risk for severe leptospirosis by molecular analysis of environmental surface waters for pathogenic Leptospira," PLoS Medicine, vol. 3, no. 8, article e308, 2006.

[27] H. Noguchi, "Spirochaeta icterohaemorrhagiae in american wild rats and its relation to the japanese and european strains: first paper," Journal of Experimental Medicine, vol. 25, no. 5, pp. 755-763, 1917.

[28] J. Shukla, U. Tuteja, and H. V. Batra, "16S rRNA PCR for differentiation of pathogenic and non-pathogenic Leptospira isolates," Indian Journal of Medical Microbiology, vol. 21, no. 1, pp. 25-30, 2003.

[29] C. M. Romero-Vivas, D. Thiry, V. Rodríguez et al., "Molecular serovar characterization of Leptospira isolates from animals and water in Colombia," Biomedica, vol. 33, no. 1, pp. 179-184, 2013.

[30] É. F. Silva, G. M. Cerqueira, N. Seyffert et al., "Leptospira noguchii and human and animal leptospirosis, Southern Brazil," Emerging Infectious Diseases, vol. 15, no. 4, pp. 621-623, 2009.

[31] S. N. Mohamed-Hassan, A. R. Bahaman, A. R. Mutalib, and S. Khairani-Bejo, "Serological prevalence of leptospiral infection in wild rats at the national service training centres in Kelantan and Terengganu," Tropical Biomedicine, vol. 27, no. 1, pp. 30-32, 2010.

[32] A. D. Alexander, L. B. Evans, M. F. Baker, H. J. Baker, D. Ellison, and M. Marriapan, "Pathogenic leptospiras isolated from Malaysian surface waters," Journal of Applied Microbiology, vol. 29, no. 1, pp. 30-33, 1975.

[33] S. Thayaparan, I. D. Robertson, and M. T. Abdullah, "Leptospiral agglutinins in captive and free ranging non-human primates in Sarawak, Malaysia," Veterinary World, vol. 7, no. 6, pp. 428431, 2014.

[34] U. Kositanont, K. Chotinantakul, D. Phulsuksombati, and C. Tribuddharat, "Assessment of Southern blot ribotyping for differentiation of Leptospira strains isolated from field rats," Journal of Microbiological Methods, vol. 69, no. 2, pp. 288-297, 2007.

[35] A. Jafari Dehkordi, H. R. Shahbazkia, and N. Ronagh, "Evaluation of pathogenic serovars of leptospira interrogans in dairy cattle herds of shahrekord by PCR," Iranian Journal of Microbiology, vol. 3, no. 3, pp. 135-139, 2011.

[36] A. García, R. Martínez, L. García et al., "Prevalence of Shiga toxin-producing Escherichia coli and pathogenic Leptospira spp. in rodents from outdoor farms in Western Spain," Turkish Journal of Veterinary and Animal Sciences, vol. 37, no. 6, pp. 750753, 2013. 


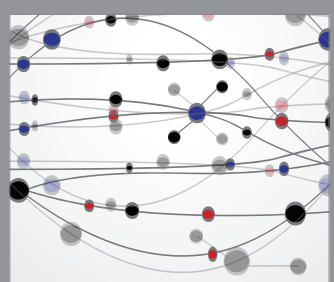

The Scientific World Journal
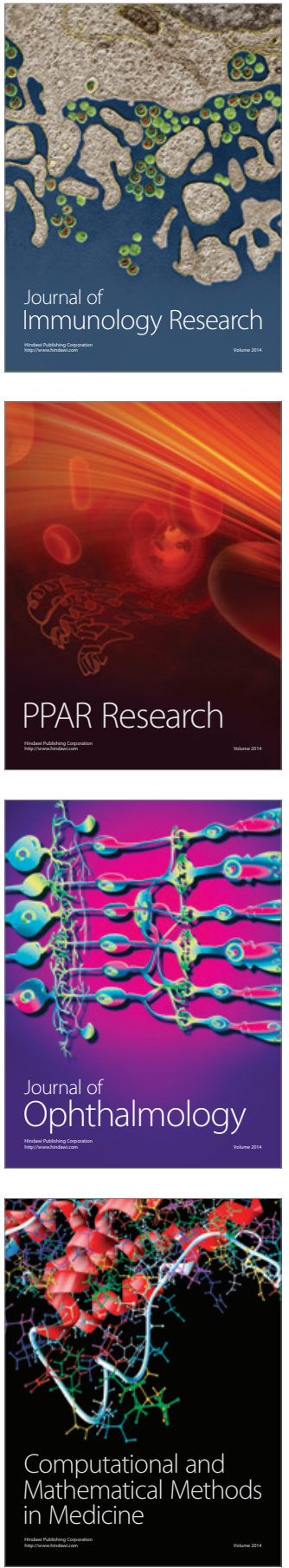

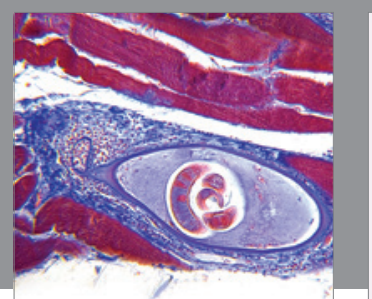

Gastroenterology Research and Practice
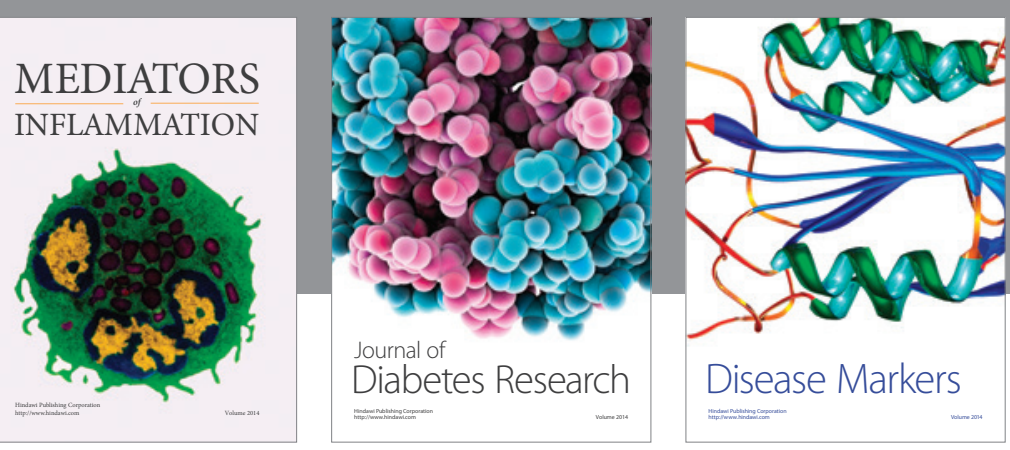

Disease Markers

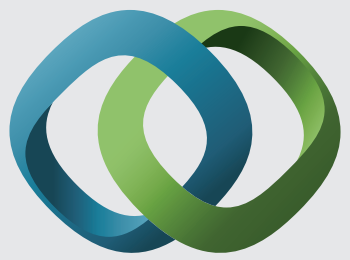

\section{Hindawi}

Submit your manuscripts at

https://www.hindawi.com
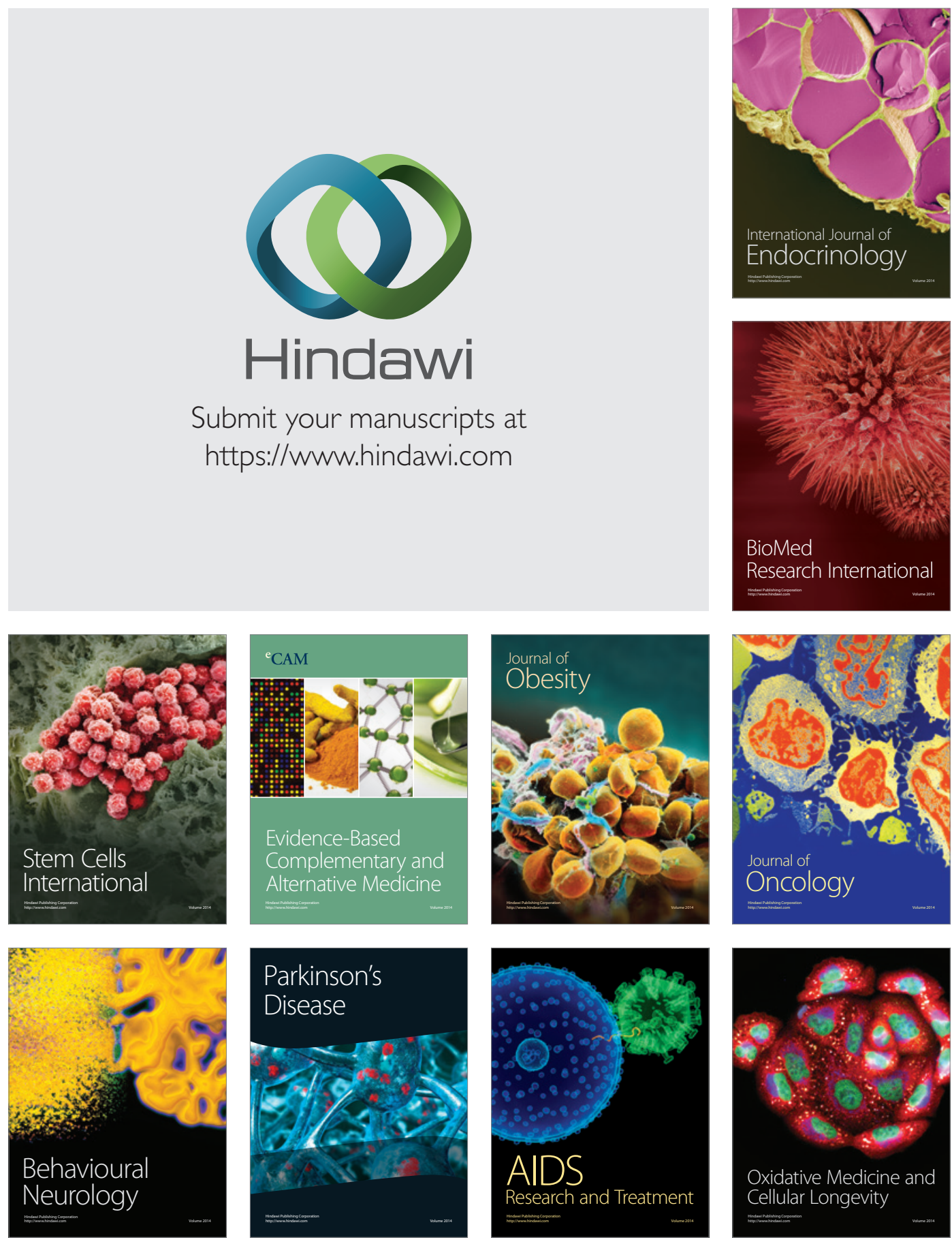